\title{
A Rare Case of Morbidly Adherent Placenta in a Young Primipara managed Conservatively
}

\author{
${ }^{1}$ Manjeet Kaur, ${ }^{2}$ Beant Singh, ${ }^{3}$ Balwinder Kaur, ${ }^{4}$ Santosh Kumari
}

\begin{abstract}
Placenta accreta syndrome is any placental implantation with abnormally firm adherence to myometrium because of partial or complete absence of decidua basalis and imperfect development of fibrinoid and Nitabuch's layers. We report a case of densely adherent placenta in a 21-year-old primipara without any other risk factor. She was referred from $\mathrm{CHC}$ Barnala following preterm vaginal delivery at 36 weeks 3 days with two failed attempts of manual removal of the placenta (MROP) where only a few bits of placenta could be removed. The ultrasonography (USG) confirmed retained adherent placenta with increased vascularity on color Doppler. Patient was managed conservatively with $50 \mathrm{mg}$ inj methotrexate intramuscularly, single dose given followed by placental expulsion 10 days later. Repeat USG confirmed normal empty uterus. Patient was discharged in satisfactory condition.
\end{abstract}

Keywords: Manual removal of the placenta, Methotrexate, Piecemeal, Placenta accreta.

How to cite this article: Kaur M, Singh B, Kaur B, Kumari S. A Rare Case of Morbidly Adherent Placenta in a Young Primipara managed Conservatively. World J Anemia 2018;2(1):36-38.

Source of support: Nil

Conflict of interest: None

\section{CASE REPORT}

A 21-year-old primipara was referred to Rajindra Hospital, Patiala, Punjab, India, following spontaneous preterm vaginal delivery at 36 weeks 3 days of a live male baby of $2.25 \mathrm{~kg}$ at CHC Barnala. Labor lasted for 10 hours. The patient had a history of one episode of bleeding per vaginum at 28 weeks gestation for which she did not get any treatment, but USG showed fundoposterior placenta with no retroplacental clots. The past medical or surgical history was insignificant. Patient denied history of dilation and curettage $(\mathrm{D} \& \mathrm{C})$ or uterine surgery. Following vaginal delivery, the placenta was retained. The MROP

\footnotetext{
${ }^{1}$ Professor, ${ }^{2}$ Assistant Professor, ${ }^{3}$ Associate Professor, ${ }^{4}$ Junior Resident

${ }^{1-4}$ Department of Obstetrics and Gynecology, Rajindra Hospital Patiala, Patiala, Punjab, India

Corresponding Author: Beant Singh, Assistant Professor Department of Obstetrics and Gynecology, Rajindra Hospital Patiala, Patiala, Punjab, India, e-mail: bsinghgyn@gmail.com
}

was tried at Barnala, when only small placental pieces could be removed. Patient was then referred to our hospital with oxytocin drip and misoprostol kept vaginally. Upon arrival to Rajindra Hospital, Patiala, on Sep 13, 2015, she was hemodynamically stable without significant bleeding. Her hemoglobin was $9 \mathrm{gm} \%$. She was afebrile and uterine height was 20 weeks in size. The intravenous antibiotics were started. The MROP was tried again, but placenta could not be removed as it was morbidly adherent to fundus. One packed cell volume was transfused. Patient was kept under observation. Uterine size was 18 weeks on posteroanterior (P/A) view. The USG showed a $9 \times 7 \mathrm{~cm}$ heterogeneous mass in endometrial cavity without any endomyometrial interphase, which on color Doppler showed increased peripheral vascularity indicating morbidly adherent placenta (Fig. 1).

Injection methotrexate $50 \mathrm{mg}$ im single dose was given. Patient expelled placental tissue on 8th day of methotrexate as shown in Figure 2 and major chunk $(10 \times$ $6 \times 3 \mathrm{~cm}$ ) on 10th postpartum day, which was confirmed on histopathological examination (Fig. 3).

On P/A, uterus was not palpable and was 10 to 12 weeks in size on $\mathrm{P} / \mathrm{V}$ examination. Patient developed fever with urinary tract infection on 8th postpartum day. All required investigations were done. The total leukocyte count and differential leukocyte count (DLC) were normal; vaginal culture was normal. Urine culture showed Escherichia coli growth, which responded to

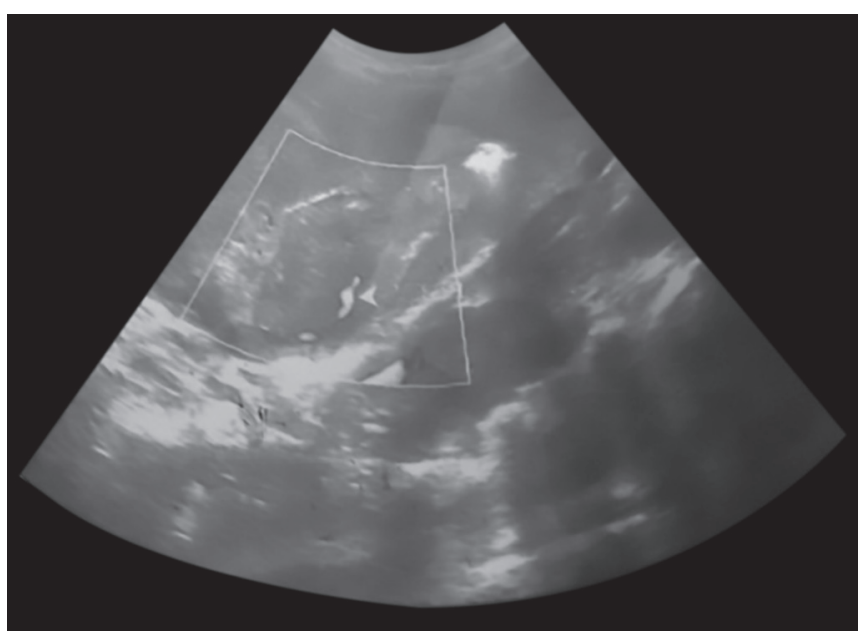

Fig. 1: The USG suggestive of retained products of conception with increased peripheral vascularity 


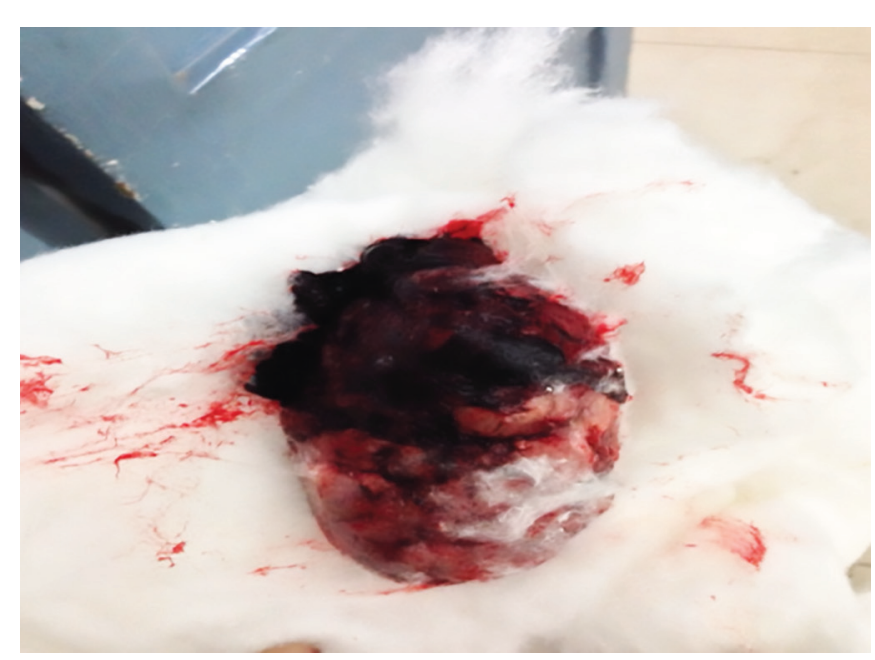

Fig. 2: Placental tissue expelled on 8th day of methotrexate (10th postpartum day)

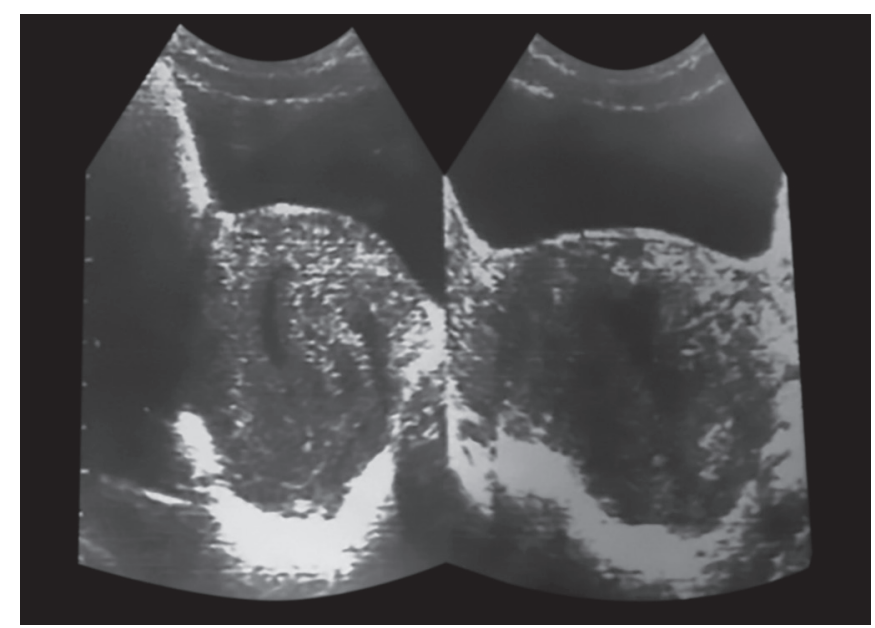

Fig. 4: The USG was done on 13th day of methotrexate injection $\mathrm{S} / \mathrm{O}$; no retained products of conception with normal empty uterine cavity

antibiotics, fever subsided. No other complication was noted. Lochia was normal. On 16th postpartum day, USG confirmed empty uterine cavity, no fibroid or septum or anomaly noted (Fig. 4). Patient was asymptomatic, afebrile, and was discharged in satisfactory condition.

\section{DISCUSSION}

The incidence of placenta accreta is as high as 1 in 533 deliveries (ACOG 2012b). ${ }^{1}$ Etiology has been postulated to be related to the damage of deciduas basalis, which allows placental invasion into the myometrium. Several risk factors identified are previous uterine surgery, lower (uterine) segment cesarean section, myomectomy, Asherman syndrome, submucosal fibroid, previous D\&C, placenta previa, increased maternal age $>35$ years, multiparity, and previous trophoblastic diseases. ${ }^{2}$ Placenta percreta is associated with maternal mortality as high as $10 \%$ with significant maternal morbidity, including massive hemorrhage, disseminated

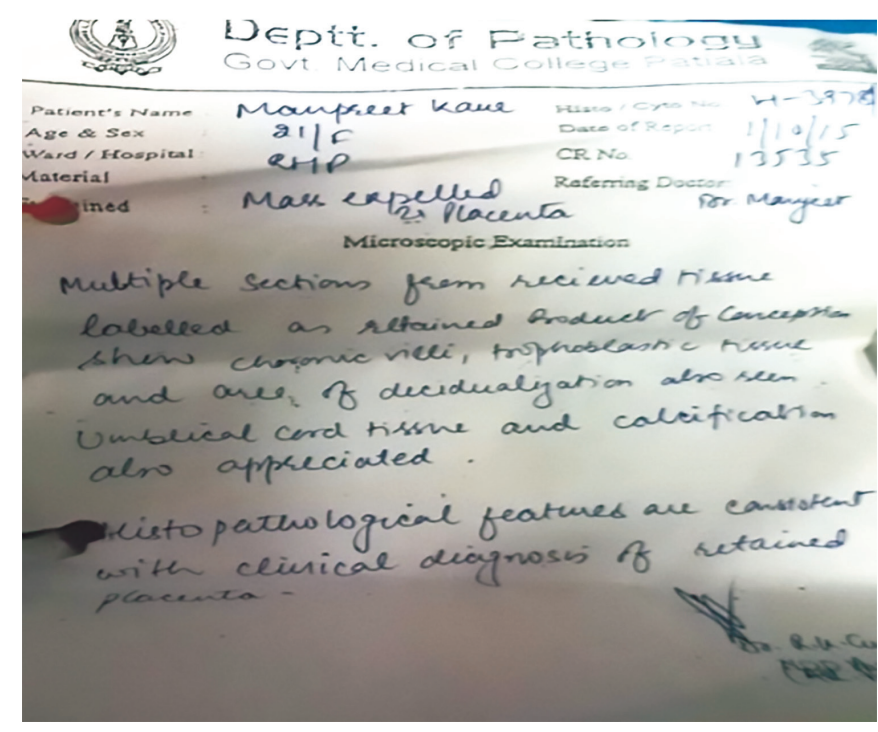

Fig. 3: Histopathology report of the major chunk expelled on 10th postpartum day suggestive of placental tissue

intravascular coagulation, acute renal failure, acute tubular necrosis, hysterectomy, bladder and ureteric injury, and acute respiratory distress syndrom have been reported. ${ }^{3}$ Methotrexate has been described as an adjuvant therapy for the conservative management of placenta accreta. This management with methotrexate is now an acceptable, reliable alternative to radical surgery, especially when future fertility is desired. Systemic administration of methotrexate has been used in majority of cases although the route of administration, treatment schedule, and total dose prescribed vary considerably. ${ }^{4}$ It has been hypothesized that methotrexate acts by inducing placental necrosis and expediting a more rapid involution of placenta. This contradicts the belief that methotrexate acts on rapidly dividing cells, given that trophoblast proliferation fails to occur at term. ${ }^{5}$ Follow-up to ensure the resolution of placental tissue is done with combination of clinical assesements, USG examination, and serial human chorionic gonadotropin assay. ${ }^{6,7}$ The USG is useful in assessing the placental involution. It has been combined with color Doppler imaging to determine placental vascularity.

\section{CONCLUSION}

In the present case, there was no identifiable risk factor as the patient was young primipara without any uterine surgery or known infections in the past, which make this case a rare one. Conservative management with methotrexate and supportive therapy was successful in this case.

\section{REFERENCES}

1. American College of Obstetricians and Gynecologists (ACOG). Placenta accreta. Committee Opinion No. 529. Obstet Gynecol 2012;120:207-211. 
2. Khadra M, Obhrai M, Keriakos R, Johanson R. Placenta percreta revisited. J Obst Gynaecol 2002 Nov;22(6):689.

3. Bennett MJ, Sen RC. 'Conservative' management of placenta praevia percreta: report of two cases and discussion of current management options. Aust N Z J Obstet Gynaecol 2003 Jun;43(3):249-251.

4. Adair SR, Elamin D, Tharmaratnam S. Placenta increta; conservative management-a successful outcome. Case report and literature review. J Matern Fetal Neonatal Med 2004 Apr;15(4):275-278
5. Cunningham, GF.; Leveno, KJ.; Bloom, SL.; Spong, CY.; Dashe, JS.; Hoffman, BL.; Casey, BM.; Sheffield, JS. Obstetrical hemorrhage. In: Williams obstetrics. 24th ed. New York: McGraw Hill; 2014. pp. 804-807.

6. Tong SY, Tay KH, Kwek YC. Conservative management of placenta accreta: review or three cases. Singapore Med J 2008 Jun;49(6):e156-e159.

7. Riggs JC, Jahshan A, Schiavello HJ. Alternative conservative management of placenta accrete. A case report. J Reprod Med 2000 Jul;45(7):595-598. 